\title{
$\mathrm{B} 3 \mathrm{G}$ 이종 액세스 망에서의 자원관리 프레임워크 연구 \\ 이종찬 ${ }^{1}$, 이기성 $2^{*}$ \\ ${ }^{1}$ 군산대학교 컴퓨터정보공학과, ${ }^{2}$ 호원대학교 컴퓨터 · 게임학부
}

\section{The Design of Framework for Resource Management in B3G Heterogeneous Access Networks}

\author{
Jong-Chan Lee ${ }^{1}$ and Gi-Sung Lee ${ }^{2^{*}}$ \\ ${ }^{1}$ Dept. of Computer Information Eng., Kunsan National University \\ ${ }^{2}$ Div. of Computer and Game, Howon University
}

\begin{abstract}
요 약 상이한 망이 공존하는 LTE-Advanced에서 기존 음성 서비스에 적용된 절차적이고 정적인 제어방식으로는 서비스 연속성을 효과적으로 지원하는 것은 현실적으로 어렵다고 여겨진다. 본 연구에서는 QoS 지원을 기반으로 서 비스 연속성을 효과적으로 지원하기 위한 자원 관리 프레임워크를 제시하고자 한다. 제안된 자원 관리 프레임워크는 이동 단말기 및 기지국의 상태 정보 변화에 따라 관련 기능- ISHO, 셀 선정, 자원 할당, 부하 제어, QoS 매핑 등-의 설정을 동적으로 제어하고, 각각의 기능들이 변화에 적응하여 조정되고 재구성하는 과정을 주고받으면서 서비스 연 속성을 만족시키기 위하여 상호 작용한다. 이를 위하여 4 종류의 ISHO를 지원하기 위한 각 모듈간의 연계 순서도를 기술하고, ISHO 시나리오가 고려된다.
\end{abstract}

\begin{abstract}
In LTE-Advanced that different networks coexist, it is considered that it is actually difficult to provide service continuity with a procedural and static control method applied to the existing voice service. This research suggests a resource management framework to support the service continuity effectively based on QoS support. In other words, as context information of mobile terminal and base station changes, set-up of related functions such as ISHO, cell selection, source allocation, load control, and QoS mapping is adapted; each function fits into the change, exchanges the process of reorganization, and interacts; these actions go toward to satisfy service continuity. For this aim, the sequence diagram between the function modules for supporting four kind of ISHO is described and then a scenario for ISHO is considered.
\end{abstract}

Key Words : LTE-Advanced, ISHO, Resource Allocation, PEP, PDP

\section{1. 서론}

WCDMA 망이 R6까지 발전하면서 다운링크(downlink) $14.4 \mathrm{Mbps}$, 업링크(up-link) $5.8 \mathrm{Mbps}$ 의 고속 데이터 를 지원할 수 있게 되었지만, 향후 4세대 이동통신으로 진화하기 위해서는 망의 구조와 성능을 높여야 할 필요 성이 제기되었다. 이에 따라 ITU는 $4 \mathrm{G}$ 이동통신 기술을 IMT-Advanced로 규정하고, 높은 전송률, 망 융합, 끓임
없는 연결(seamless connection) 등을 특징으로 정의하고 있으며, 현재 위의 요건을 충족시키는 기술로서 $3 \mathrm{GPP}$ 의 LTE(Long Term Evolution)-Advanced가 주목받고 있다 [1-3]. LTE-Advanced에서는 Hot-spot(예를 들어 WiFi) 영 역 위주로 고속 데이터 통신을 지원하고, Hot-spot 이외 의 지역에는 기존의 시스템과의 연동을 통해 어느 지역 에서든 하나의 MT로 Terminal mobility와 Session mobility 시에 서비스 연속성을 제공해야 한다. 그러나 상

이 논문은 2011년도 군산대학교 교수장기국외연수경비의 지원에 의하여 연구되었음

"Corresponding Author : Gi-Sung Lee

Tel: +82-10-2866-5170 email: ygslee@howon.ac.kr

접수일 12 년 09 월 04 일 수정일 12 년 10 월 04 일 개재확정일 12 년 11 월 08 일 
이한 망이 공존하는 LTE-Advanced에서 서비스 연속성을 효과적으로 지원하는 것은 현실적으로 어려운 문제로서 LTE-Advanced 망을 형성하는 리소스 및 망의 형상(대역, 에러 율 등)들이 가변적으로 변하기 때문에 기존 음성 서 비스에 적용된 절차적이고, 인위적이고, 정적인 제어방식 으로는 제어가 불가능하다고 판단하고 있다. 특히 다양하 고 이질적인 통신 시스템들은 All-IP 기반의 다중 망을 통하여 연동되며[4-7], 이러한 All-IP 기반 멀티미디어 응 용을 효율적으로 지원하기 위하여 이종으로 구성되는 액 세스 망에서의 자원 관리(resource management)가 중요한 문제가 된다. 다양한 유무선 시스템들의 IP 기반의 백본 에 연결되어 있는 구조에서 사용자 및 운영자가 원하는 $\mathrm{QoS}$ 를 제공하기 위해서는 응용의 특성에 따라 소스 및 대응 단말이 접속하는 접속 망에서의 효율적인 자원 관 리 방안의 제공이 필수적이다[7-9].

따라서 다양한 이종의 액세스 망들이 공존하는 융합망 환경에서 TE/H-BS/H-AN/IP-CN에 위치하는 계층 별 자 원 관리 블록 간의 연계성을 갖는 자원 관리 망을 구축하 고 시스템 운영자의 자원 운영 정책과 망의 상태에 따라 적응적으로 자원을 관리함으로서 사용자 및 운영자가 원 하는 목표 품질을 보장하고, 계획된 유효 서비스 영역을 유지하고, 높은 시스템 용량을 제공할 수 있다. 이를 위하 여 정책 기반의 자원 관리(QoS Adaptive Resource Management; 이하 QARM) 프레임워크를 제안한다. 또한 이를 기반으로 $\mathrm{MT}$ 의 이동 및 현재 상태 그리고 이종망 의 상태 등에 따라 3 종류의 시스템 간 핸드오버 (inter-System handover; 이하 ISHO)를 지원하기 위한, 각 모듈간의 연계 순서도 및 ISHO 시나리오를 제시한다. 이 는 3 종류의 ISHO 특성에 따라, 망 관리자의 이종망 운 영 정책에 근거하며, 자원 관리 기능들이 가변적으로 변 화하고 이 변화된 자원 관리 기능들을 적용함으로서, 최 적의 성능을 갖도록 한다.

\section{2. 이종망과 QARM}

QARM의 정책 응용 계층은 RM-PMT(Policy Management Tool)로서 자원 관리 정책을 지시하고 변경하고 디 스플레이 하는 사용자 인터페이스를 제공한다. 또한 관리 되고 있는 장치의 자원 관리 상태를 표시한다. 정책 제어 계층은 RM-PR(Policy Repository)와 RM-PDP(Policy Decision Point)로 구성된다. RM-PR은 정책 정보를 저장 하고 입출력하는 디렉토리 서비스 저장 장치이고, RM$\mathrm{PDP}$ 는 실제 정책을 결정하고 각각의 하위 기지국에 결정된 정책을 전달하는 장치이다. RM-PEP(RM-Policy Enforce- ment Point; 이하 RM-PEP)는 실제 자원 관리가 발생하는 부분이다. 이 부분이 실제 정책 실행점이 되며 정책 서버 가 실제 각 이종망의 상황을 모니터링 하고 각 정책에 대 한 데이터베이스를 가지고 있어서 이종망 각각의 기지국 에 대하여 세션 제어(session control), $\mathrm{QoS}$ 제어(QoS control), 핸드오버 제어 등을 망 상황에 따라 동적으로 제어하게 된다. 정책서버와 하위 기지국과의 통신은 $\mathrm{COPS}$ 를 사용한다. 이러한 정책은 사람이 이해할 수 있는 형태로 망 관리자에 의해 RM-PMT를 사용해서 만든다. RM-PMT는 이를 해석하여 시스템에 알맞은 형태로 $\mathrm{RM}-\mathrm{PR}$ 에 다시 저장한다. RM-PDP는 복잡한 정책 변환 과 해석을 통해 정책 결정을 수행하고 RM-PEP는 $\mathrm{RM}-\mathrm{PDP}$ 가 보내준 정책 결정에 따라 그에 맞는 자원 관 리를 수행한다[10].

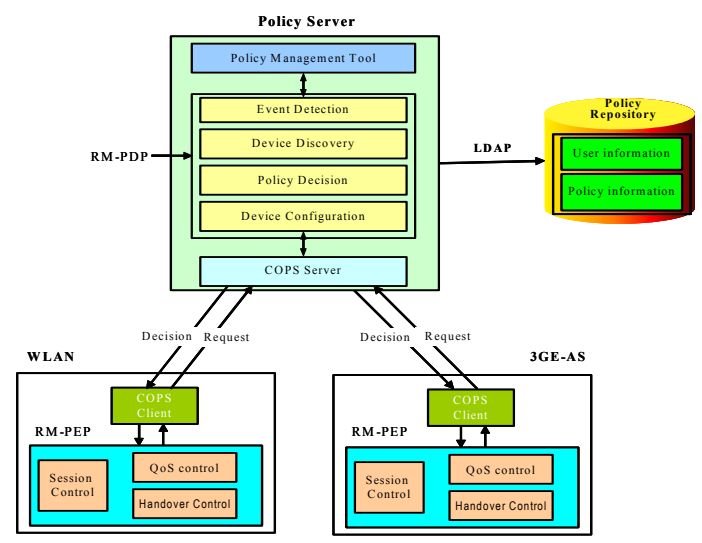

[그림 1] 정책 교환 (RM-PEP $\leftrightarrow$ RM-PDP)

[Fig. 1] Policy Exchange (RM-PEP $\leftrightarrow$ RM-PDP)

그림 1 과 같이 RM-PEP와 RM-PDP 간에 정책 교환 및 설정을 위해 COPS를 사용한다. COPS는 급변하는 이종 망 상황에 따라 또는 가입자 가입조건의 변화에 따라 동 적으로 정책이 바뀌는 경우에 사용한다. 동적으로 이벤트 가 발생하면 RM-PDP는 즉시 정책을 결정하고 $\mathrm{COPS}$ 서 버를 사용하여 그 정책이 필요한 RM-PEP(하위의 기지국 또는 제어국)의 COPS 클라이언트에게 COPS 프로토콜을 사용하여 정책- 세션 제어, $\mathrm{QoS}$ 제어, 핸드오버 제어를 요구한다.

\section{RM-PEP의 자원관리 프레임워크}

\section{1 기반 구조}

QARM은 서비스 제공을 위하여 SLA(Service Level 
Agreement) 기반의 QoS 관리 방안을 적용한다. SLA가 사용자와의 계약에 의하여 생성될 때, 각 망에서 자원을 제공하거나 할당하기 위하여 제공되는 한 개 이상의 SLS(Service Level Specifications)가 생성된다. SLS로 부 터의 $\mathrm{QoS}$ 파라미터는 $\mathrm{QARM}$ 에 전송되고, 이를 근거로 하여, 사용자의 $\mathrm{QoS}$ 수준이 각 이종망에서 제공된다. 본 연구에서 제안한 $\mathrm{QARM}$ 의 구조가 그림 2에 보인다.
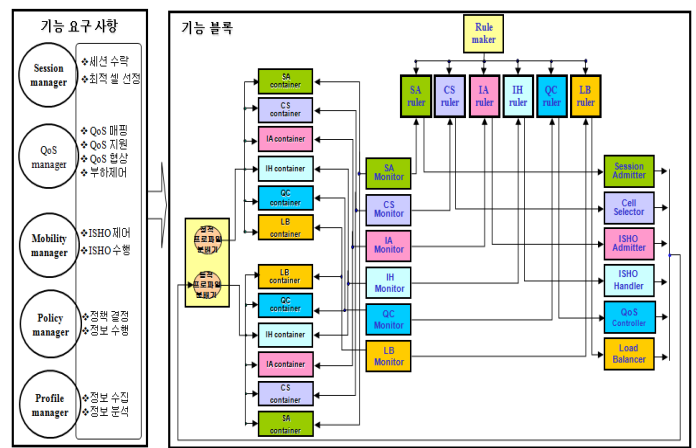

[그림 2] 자원 관리를 위한 RM-PDP 모듈

[Fig. 2] RM-PDP for Resource Management

\subsection{RM-PDP의 핸드오버 관련 제어 구조}

이종망 상에서 발생하는 ISHO는 이동을 통한 핸드오 버뿐만 아니라 셀 내에서 서비스 중에 $\mathrm{QoS}$ 가 저하될 경 우, 특정 접속 망의 부하가 가중할 경우 그리고 높은 수 준의 $\mathrm{QoS}$ 로의 요구가 발생할 경우에 발행할 수 있다. 각 기 다른 특성을 갖는 $\mathrm{ISHO}$ 의 수용 여부를 결정하기 위하 여 ISHO admitter는 4 개의 하위 모듈을 두고, ISHO 요 구를 처리한다. 이종망에서 고려해야할 $\mathrm{ISHO}$ 를 분류하 면 표 1과 같다[11-16].

[표 1] ISHO의 분류

[Table 1] Classification of ISHOs

\begin{tabular}{|c|c|}
\hline 기능 & 역할 \\
\hline $\begin{array}{c}\text { U-ISHO } \\
\text { (Upgrading ISHO) }\end{array}$ & QoS 증대 요구에 의하여 발생 \\
\hline $\begin{array}{c}\text { M-ISHO } \\
\text { Moving ISHO) }\end{array}$ & MT의 이동에 의하여 발생 \\
\hline $\begin{array}{c}\text { B-ISHO } \\
\text { (Balancing ISHO) }\end{array}$ & $\begin{array}{c}\text { 특정 셀 또는 접속 망의 부하가 } \\
\text { 가중할 경우에 발생 }\end{array}$ \\
\hline $\begin{array}{c}\text { D-ISHO } \\
\text { (Degrading ISHO) }\end{array}$ & $\begin{array}{c}\text { QoS 저하(전송지연, 패킷 손실)에 } \\
\text { 의하여 발생 }\end{array}$ \\
\hline
\end{tabular}

\subsubsection{M-ISHO 처리 절차}

M-ISHO 시에 고려해야 할 사항은 세션에 대하여 정 해진 QoS 수준에 대한 재정의이다. 만일 ISHO 이후에도
동일한 $\mathrm{QoS}$ 수준을 유지할 수 없다면 $\mathrm{QoS}$ 재협상 (Renegotiation)이 필요하다. M-ISHO adapter는 이러한 $\mathrm{M}-\mathrm{ISHO}$ 시의 $\mathrm{QoS}$ 조정에 관여한다. RM-PEP로부터 ISHO 요구에 대한 COPS REQ를 수신한 RM-PDP의 IA monitor는 정보 분석을 수행하고, 이 결과를 IA ruler 에 게 전송한다. IA ruler는 분석 결과가 조건에 부합할 경 우, 정책 규칙(rule)을 $\mathrm{M}-\mathrm{ISHO}$ admitter에게 전송하고, $\mathrm{M}-\mathrm{ISHO}$ 는 수락 여부를 결정하며, Cell selector에서 ISHO할 최적의 셀을 선정한다.

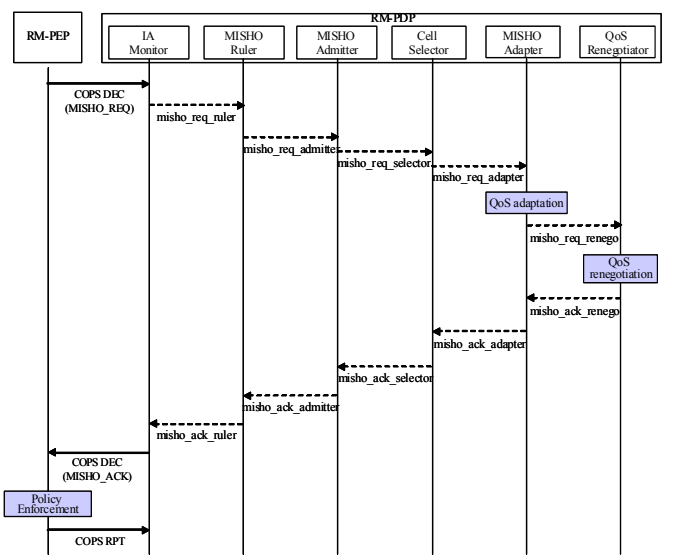

[그림 3] QARM에서의 M-ISHO 처리 절차도

[Fig. 3] M-ISHO procedure in QARM

이후, 선정된 이종망 셀로의 $\mathrm{QoS}$ 변경을 요구한다. $\mathrm{QoS}$ 변경 요청을 받은 M-ISHO adapter 는 선정된 핸드 오버 셀에서 제공 가능한 $\mathrm{QoS}$ 수준을 결정하고, 해당 세 션에 대해 QoS에 적합한 자원을 할당한다. 하지만 만일 서비스 $\mathrm{QoS}$ 수준 변경이 불가피할 경우 세션에 대한 재 협상을 수행한다. 그림 3에 M-ISHO 처리 절차를 보인다.

\subsubsection{B-ISHO}

Load balancer에 의하여 이루어지는 부하 분산은 특정 셀에 트래픽 과부하 발생할 경우 동일한 $\mathrm{QoS}$ 를 유지하면 서 이종망으로의 ISHO를 통하여 부하를 분산시키는 기 능을 수행한다. 만일 동일한 $\mathrm{QoS}$ 를 유지하면서 다른 이 종망으로의 부하 분산(load balancing)이 가능하다면 일부 세션에 대한 ISHO이 가능하다.

그림 4는 이종망으로의 부하 분산 과정을 보이고 있 다. LB monitor의 정보 분석에 의하여 과부하(overload) 가 감지되면 이를 $\mathrm{LB}$ ruler에게 통보하여 정책 결정을 받 는다. Load balancer는 정책 규칙에 근거한 우선순위에 의하여 ISHO를 수행할 서비스 세션들을 선정한 후, 선정 된 세션에 대하여 B-ISHO 수락 여부 결정, 셀 선정, $\mathrm{QoS}$ 
조정, 그리고 재협상이 필요하다면 QoS 재협상을 통하여 부하 제어 과정을 수행한다.

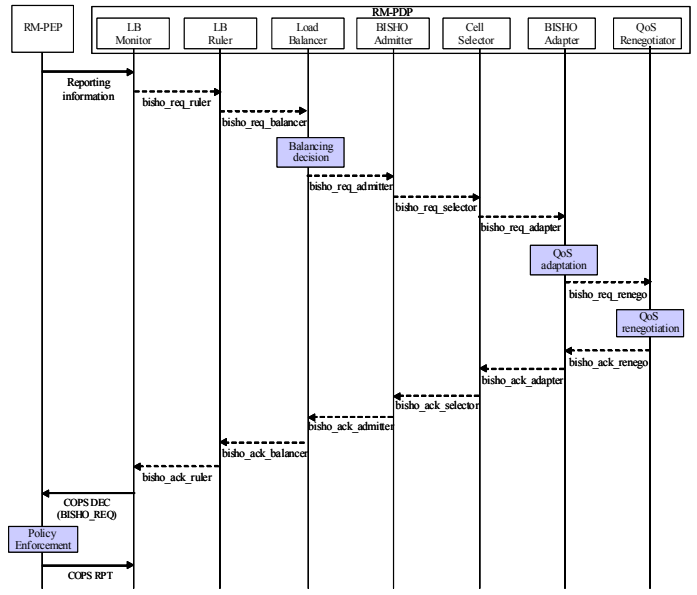

[그림 4] QARM에서의 B-ISHO 처리 절차도

[Fig. 4] B-ISHO procedure in QARM

\subsubsection{U-ISHO 처리 절차}

세션의 QoS 상승 요구로 인하여 U-ISHO를 수행할 수 있다. MT로부터 QoS 향상 요구가 발생하면, RM-PEP는 RM-PDP에게 COPS REQ 메시지를 보낸다. QoS 향상에 관한 COPS REQ 메시지를 수신한 RM-PDP는 이미 설정 된 정책 규칙을 통해 알맞은 정책 결정을 하고 해당 $\mathrm{RM}-\mathrm{PEP}$ 에게 정책에 맞는 실행을 할 수 있도록 정책 정 보를 포함하여 COPS DEC 메시지를 전달한다. COPS $\mathrm{DEC}$ 메시지를 받은 RM-PEP는 이 정책 결정에 맞는 행 동(action)을 실행하고 COPS RPT 메시지를 RM-PDP에 게 되돌려 보낸다. 그림 5 에 그 절차를 보인다.

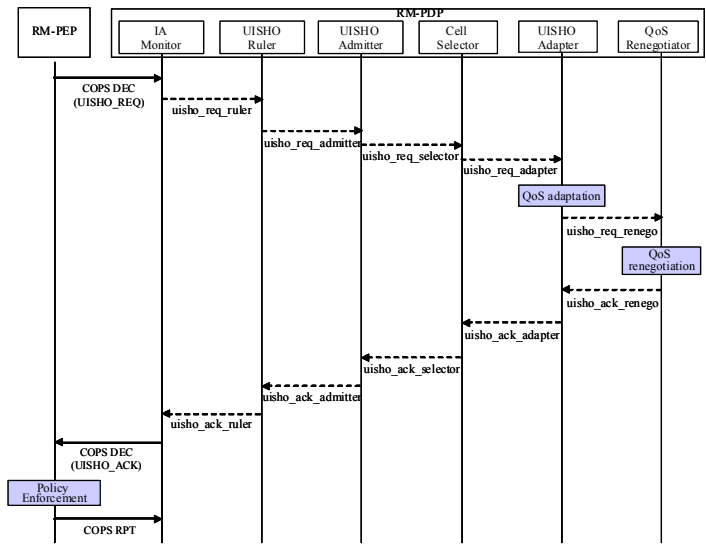

[그림 5] QARM에서의 U-ISHO 처리 절차도

[Fig. 5] U-ISHO procedure in QARM

\section{4. 시나리오}

\subsection{M-ISHO 시나리오}

기존의 핸드오버처럼 MT가 서비스 지역을 벗어나면 서 발생하는 신호 세기 기반의 $\mathrm{ISHO}$ 이다. 만일 $\mathrm{WiFi}$ 이 LTE-AS 지역 내부에 설치되어 있다면, 이 경우 발생하는 $\mathrm{ISHO}$ 는 $\mathrm{WiFi}$ 에서부터 LTE-AS로의 핸드오버이다. 이 과 정을 그림 6에 보인다.

$\mathrm{MT}$ 가 $\mathrm{WiFi}$ 지역을 벗어난다면 $\mathrm{WiFi} \mathrm{AP}$ 로 도달하는 전파의 신호 세기가 낮아지면서 LTE-AS의 E-Node B로 부터의 신호 세기가 증가한다. MT는 M-ISHO REQ 메시 지를 $\mathrm{WG}(\mathrm{WiFi}$ Gateway)-PEP를 경유하여 RM-PDP에게 전달한다. RM-PDP는 E-SN-PEP에게 M-ISHO를 위한 연 결 설정에 대한 요구와 $\mathrm{MT}$ 에 대한 정보를 제공하고, E-SN-PEP는 E-SN과 Node B에 대해 핸드오버에 대한 연 결 재설정을 요구한다. 이를 통하여 LTE-AS 망에서 MT 에 대한 새로운 연결 설정 및 자원 할당이 수행되며, 이 결과를 RM-PDP에 전송한다. 연결에 대한 승인을 받은 $\mathrm{RM}-\mathrm{PDP}$ 는 E-SN-PEP를 통하여 MT에 대해 ISHO의 성 공적인 수행을 유도한다.

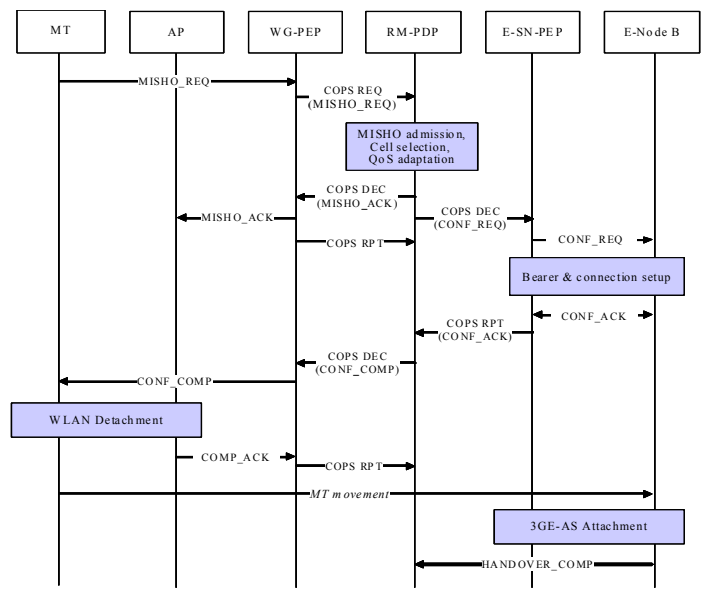

[그림 6] M-ISHO 시나리오

[Fig. 6] M-ISHO Scenario

\subsection{U-ISHO 시나리오}

$\mathrm{U}-\mathrm{ISHO}$ 는 기존의 MT의 이동에 의한 ISHO가 아닌 종 단간 QoS 상승을 위하여 수행하는 핸드오버로서 세션의 서비스 중에 다른 중첩된 이종망으로 $\mathrm{QoS}$ 상승을 위하여 세션의 ISHO를 수행해야 한다. LTE-AS에서 WiFi로 $\mathrm{QoS}$ 상승을 위한 U-ISHO를 수행하기 위해서는, $\mathrm{WiFi}$ 에 서는 LTE-AS의 서비스 수준 보다 더 높은 트래픽 전송 수준을 제공해야 한다. 또한 $\mathrm{WiFi}$ 에서 심각한 트래픽 과 
부하로 인하여 정상적인 서비스가 어려울 경우 LTE-AS 로의 서비스 전환을 수행해야 한다. 그림 7은 LTE-AS 망 에서 $\mathrm{MT}$ 가 $\mathrm{QoS}$ 상승을 위하여 $\mathrm{WiFi}$ 으로 U-ISHO를 수 행하는 절차를 보인다.

$\mathrm{MT}$ 가 LTE-AS에서 $\mathrm{WiFi}$ 지역에 진입할 경우 또는 $\mathrm{LTE}-\mathrm{AS}$ 와 $\mathrm{WiFi}$ 의 중첩 지역에 있을 경우, $\mathrm{QoS}$ 수준을 높이기 위하여 U-ISHO를 수행할 수 있으며, 이를 위하여 QoS 상승을 위한 ISHO 요구 메시지를 E-SN-PEP에게 전 달한다. U-ISHO 요구 메시지를 받은 E-SN-PEP는 $\mathrm{RM}-\mathrm{PDP}$ 에게 요구 메시지를 전달하고, RM-PDP는 QoS 상승을 위한 자원 상태를 조사하고 $\mathrm{QoS}$ 상승이 가능하 면, 이를 E-SN-PEP에게 회신하고 WG-PEP를 통하여 $\mathrm{WiFi}$ 에서 $\mathrm{U}-\mathrm{ISHO}$ 를 위한 연결 설정 및 자원할당을 수행 한다. 연결 설정 후에 $\mathrm{MT}$ 에 대해 QoS 상승을 위한 ISHO 수행을 전달한다. 만일 $\mathrm{WiFi}$ 에서의 트래픽 과부하로 인 하여 QoS 상승이 여의치 않을 경우 U-ISHO admitter가 $\mathrm{QoS}$ 상승을 위한 MT의 ISHO 요구를 거절한다. U-ISHO admitter는 자원점유지표와 MT의 외부 프로파일을 참조 하여 해당 네트워크의 자원 상태를 확인 한 후에, ISHO 수락 여부를 결정하고 이를 MT에게 전달한다.

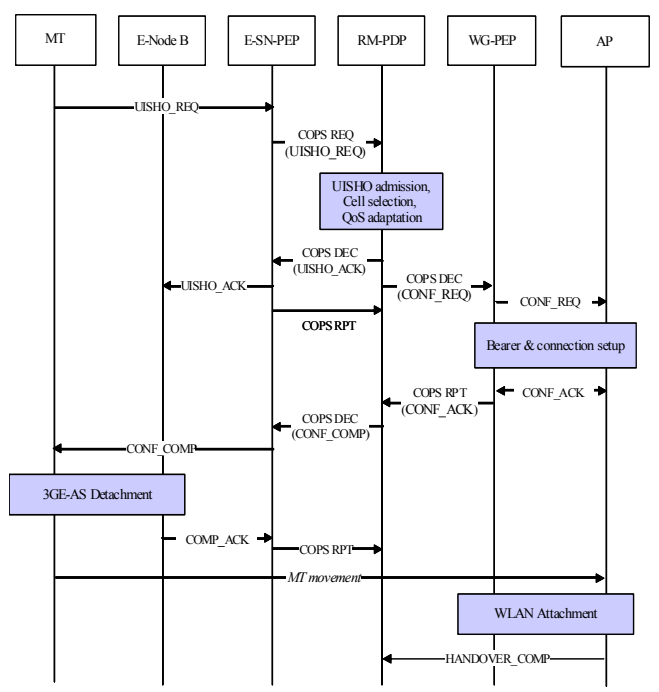

[그림 7] U-ISHO 시나리오

[Fig. 7] U-ISHO Scenario

\section{$4.3 \mathrm{~B}-\mathrm{ISHO}$ 시나리오}

$\mathrm{RM}-\mathrm{PDP}$ 의 $\mathrm{LB}$ monitor는 정책 활성화 조건(condition of firing policy; $\mathrm{CFP}$ )에 근거하여 수집된 정보를 분석하 고, 분석 결과에 따라 RM-PDP는 B-ISHO를 수행한다. $\mathrm{LTE}$ 에서의 부하 분산은 이종망을 구성하는 각각의 망에 서 발생하는 트래픽 과부하에 대한 처리 방안으로서, 이
종망에서는 부하 분산에 의하여 망의 이용률을 높일 수 있다. 여기서 고려해야 할 사항은 부하 분산 수행 여부의 판단으로서, 이는 수행에 대한 시점과 가능성을 말한다. 수행 시점은 셀의 과부하를 감지하고 B-ISHO 여부를 결 정하는 시점을 의미하고, B-ISHO 가능성은 B-ISHO가 결 정된 세션과 동일한 $\mathrm{QoS}$ 의 제공 여부를 의미한다.

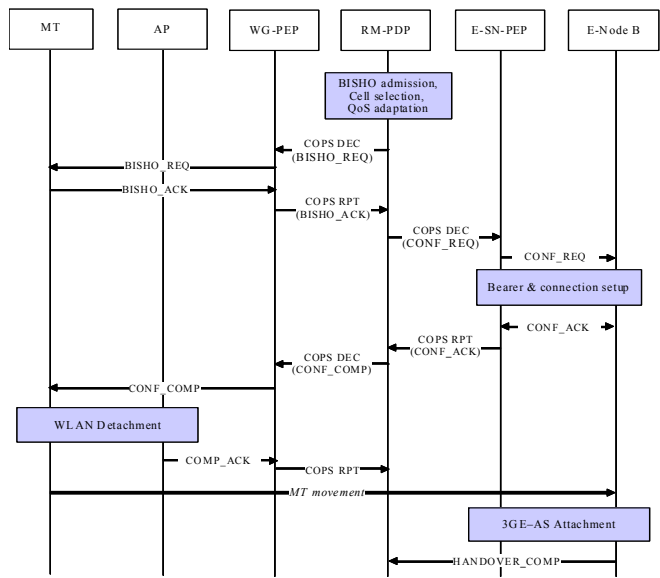

[그림 8] B-ISHO 시나리오

[Fig. 8] B-ISHO Scenario

B-ISHO는 LTE-AS에서 WiFi, WiFi에서 LTE-AS로 발 생할 수 있다. 과부하가 감지되면 Load balancer는 우선 순위에 근거하여 ISHO를 수행할 세션들을 선정한 후, 선 정된 세션에 대하여 B-ISHO 수락 여부 결정, 셀 선정, $\mathrm{QoS}$ 조정, 그리고 재협상이 필요하다면 $\mathrm{QoS}$ 재협상을 통하여 부하 제어 과정을 수행한다. 이를 그림 8 에 보인 다. 우선순위를 근거로 이종망으로 $\mathrm{B}-\mathrm{ISHO}$ 를 권고 받은 $\mathrm{MT}$ 는, B-ISHO 승인 메시지를 WG-PEP를 통하여 RM$\mathrm{PDP}$ 에 전달하고, RM-PDP는 E-SN-PEP를 통하여 연결 설정 및 자원할당을 요구한다. 이에 따라, LTE-AS 에서 $\mathrm{MT}$ 에 대한 새로운 연결 설정 및 자원 할당이 수행되며, 이 결과를 RM-PDP에 전송하고, 연결에 대한 승인을 받 은 RM-PDP는 U-ISHO를 수행한다.

\section{5. 결론}

LTE-Advanced에서는 Hot-spot 영역 위주로 고속 데이 터 통신을 지원하고, Hot-spot 이외의 지역에는 기존의 시스템과의 연동을 통해 어느 지역에서든 하나의 이동 단말기로 단말 이동과 세션 이동 시에 서비스 연속성을 제공해야 한다. 이를 위하여 본 연구에서는 정책 기반의 
자원 관리 프레임워크를 제안하고 이를 기반으로 4 종류 의 ISHO를 지원하기 위한, 각 모듈간의 연계 순서도 및 ISHO 시나리오를 제시하였다. 향후 본 논문에서 제안된 ISHO 구조의 구체화 및 알고리즘을 고도화하기 위한 세 부적인 연구가 필요하다.

\section{References}

[1] Hyun-Ho Choi; Dong-Ho Cho., "Takeover: a new vertical handover concept for next-generation heterogeneous networks," IEEE Transaction on Vehicular Technology, Vol. 4, pp 2225-2229, June 2005.

[2] K. Ayyappan and R. Kumar, "QoS Based Vertical Handoff Scheme for Heterogeneous Wireless Networks," International Journal of Research and Reviews in Computer Science, Vol. 1, No. 1, pp. 1-6, 2010.

[3] S. Frattasi and H. Fathi, "Defining 4G Technology from the User's Perspective", IEEE Network, Vol. 20, Issue 1, pp. 35-41, Jan.-Feb. 2006.

[4] A.H. Khan, M.A. Qadeer, J.A. Ansari, and S. Waheed, "4G as a Next Generation Wireless Network," International Conference on Future Computer and Communication, pp. 334-338, Apr. 2009.

[5] S. Ryu, D. Oh, G. Sihn, and K. Han. "Research Activities on the Next Generation Mobile Communications and Services in Korea," IEEE Communications Magazine, Vol.43, No.9, pp.122-131, September, 2005.

[6] D. Lee and J. Lee, "Handover Control Method Using Resource Reservation in Mobile Multimedia Networks," IEICE Transaction on Communications, Vol. 92-B, No. 8, pp. 2684-2697, Aug. 2009.

[7] Simone Frattasi, Hanane Fathi., "Defining 4G Technology from the User's Perspective," IEEE Network, Volume 20, Issue 1, January.-Feburary. pp. 35-41, 2006.

[8] P.Khadivi, T.D.Todd, S.Samavi, H.Saidi and D.Zhao, "Mobile Ad Hoc Relaying in Hybrid LAN/Cellular Systems for Dropping Probability Reduction", Proceedings of the 9th CDMA International Conference (CIC 2006), Korea, pp.25-28, March 2006.

[9] K.Ayyappan and R. Kumar, "QoS Based Vertical Handoff Scheme for Heterogeneous Wireless Networks," International Journal of Research and Reviews in Computer Science (IJRRCS), Vol. 1, No. 1, pp. 1-6, 2010 .

[10] J. Lee, G. Lee, "An End-to-End QoS Control Method for Heterogeneous Networks," Korea Academy-Industrial Cooperation Society," Vol. 10, No. 10, pp. 2715-2720, Oct. 2009.

[11] G. Lee, S. Jeong, J. Lee, S. Park, "A Policy-based Resource Management Framework for QoS Improvement of Mobile Terminals in heterogeneous Network," Korea Society of Computer Information, Vol. 15, No. 11, pp. 125-133, Nov. 2010.

[12] Ki-Young Cho, Ho-Seok Nam, Seung-Cheon Kim, Jun-Nyun Kim, "A Study on the Performance Analysis of Wireless Networks for Mobile Convergence in V2V Environments", Journal of The Institute of Webcasting, Internet and Telecommunication, VOL.11, No.3, pp. 161-168, June, 2011.

[13] Hae-SeongCho,Ju-PhilCho, "Implementation of Wireless Automatic Control System for Vehicle Interior Environment", Journal of The Institute of Webcasting, Internet and Telecommunication, VOL.10, No.5, pp. 287-291, October, 2010.

[14] Jong-Young Ahn, Young-Sub Kim, Sung-Su Kim, Kang-In Hur, "A study on Non-contacted Transmitter Switch for Vehicle", Journal of The Institute of Webcasting, Internet and Telecommunication, VOL.10, No.5, pp. 245-249, October, 2010.

[15] JunyoungHeo, "QoS-guaranteed Routing for Wireless Sensor Networks", Journal of The Institute of Webcasting, Internet and Telecommunication, VOL. 11, No. 6, pp.23-29, December, 2011.

[16] Sun-Jin Oh, "Design and Evaluation of a Weighted Intrusion Detection Method for VANETs", Journal of The Institute of Webcasting, Internet and Telecommunication, VOL.11, No.3, pp. 181-188, June, 2011.

이 종 찬(Jong-Chan-Lee)

[정회원]

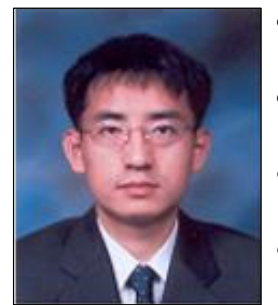

- 1996년 8월 : 숭실대학교 컴퓨터 공학과 (공학석사)

- 2000년 8월 : 숭실대학교 컴퓨터 공학과 (공학박사)

- 2000년 10월 2005년 4월 : 한 국전자통신연구원 선임연구원

- 2005년 4월 현재 : 국립군산대 학교 컴퓨터정보공학과 부교수

<관심분야>

차세대 이동통신, 센서 네트워크, 무선 멀티미디어 
이 기 성(Gi-Sung Lee)

[정회원]

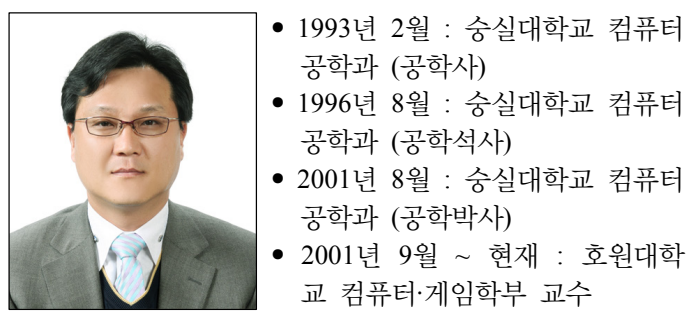

<관심분야>

이동멀티미디어통신, 모바일 컴퓨팅, 컴퓨터네트워크 보안 